\title{
Exploring the Link between Online Behaviours and Course Performance in Asynchronous Online High School Courses
}

\author{
Susan Lowes, Peiyi Lin, and Brian Kinghorn \\ Teachers College, Columbia University, USA \\ lowes@tc.edu
}

\begin{abstract}
As enrolment in online courses has grown and LMS data has become accessible for analysis, researchers have begun to examine the link between in-course behaviours and course outcomes. This paper explores the use of readily available LMS data generated by approximately 700 students enrolled in the 12 online courses offered by Pamoja Education, the course provider for the International Baccalaureate, in 2012-2013. The findings suggest that LMS data sets can indeed provide useful information on the relationship between online behaviours and final grades; that higher levels of online behaviours are associated with higher performance; that two types of behaviour, one associated with attendance and the other associated with interactivity, operate separately; and that these two types of behaviour function differently depending on gender.
\end{abstract}

Keywords: Online learning, educational data mining, learning analytics, LMS behaviours

\section{$1 \quad$ INTRODUCTION}

The last decade has seen exponential growth in enrolments in online courses at the high school level. In 2003, there were approximately 330,000 enrolments among students in public schools in the United States (NCES, 2005). By 2010, there were approximately 1.8 million, 74\% at the high school level (NCES, 2011). There were another 300,000 full-time online students in charter schools (Watson, Pape, Murin, Gemin, \& Vashaw, 2014). The vast majority of these students are taking one or two courses, generally because a course is not offered at their school but also to recover credits for failed or missed courses, to free up their schedules, or to gain experience with an online course before college (iNACOL, 2013). In a growing number of U.S. states, at least one online course is required for high school graduation (Watson et al., 2014). These online courses may be provided by state or district virtual schools, by virtual charter schools, or by private providers. At the high school level, online courses are generally asynchronous but can be either self-paced or follow a cohort-based weekly schedule. The former has been the most common model for high school courses, while the latter is more common in higher education.

Online courses generate streams of data from the Learning Management System (LMS) that can be used to provide insights into student behaviour in the online environment, especially as it relates to student success. However, although online learning at the $\mathrm{K}-12$ level has grown rapidly, research using LMS data at this level remains sparse (Lowes, 2014), especially compared to the amount of work in higher education. In addition, as we will see below, the existing research has looked at different variables and has yielded mixed and sometimes contradictory results (Davies \& Graff, 2005; Dawson, McWilliam \& 
(2015). Exploring the link between online behaviours and course performance in asynchronous online high school courses. Journal of Learning Analytics, 2(2), 169-194. http://dx.doi.org/10.18608/jla.2015.22.13

Tan, 2008; Hung, Hsu, \& Rice, 2012; Hung \& Zhang, 2008; Liu \& Cavanaugh, 2011a, 2011b, 2012; Macfadyen \& Dawson, 2010; Ramos \& Yudko, 2008; Ryabov, 2012; Wang \& Newlin, 2000; Wei, Peng, \& Chou, 2015). This paper uses LMS data generated by approximately 700 high school students who were enrolled in 12 asynchronous cohort-paced online courses offered by Pamoja Education (PJE), the course provider for the International Baccalaureate (IB), in order to explore the link between LMS behaviours and course outcomes at the high school level.

There are at least three types of interaction in online courses: learner-content, learner-teacher, and learner-learner (Moore, 1989). It is the emphasis on learner-learner interaction that distinguishes the cohort-based model of online learning adopted by PJE from self-paced models, which are more akin to independent study or tutoring. The inclusion of student-student interaction is central to the design of online courses based on constructivist learning theories (Anderson, 2003) because constructivists believe that learners need to co-construct knowledge - and therefore to interact with each other - in order to learn and retain what they have learned (Jonassen, 1999). In higher education, student-student interaction in online courses has long been considered essential for both learning and for motivation (Bernard et al., 2009). In the K-12 online environment, the need for student-student interaction has been integrated into course quality standards (i.e., Southern Regional Education Board, 2006; iNACOL, 2011). IB courses are explicitly constructivist in design (International Baccalaureate, 2013) and PJE's course designers build in multiple opportunities for student-student interaction, primarily through discussion forums and group projects. We were therefore particularly interested in the contribution of LMS behaviours relating to student-student interaction to course outcomes.

\section{PRIOR RESEARCH ON ONLINE BEHAVIOURS}

The research using LMS data has found that higher levels of activity are almost always associated with better outcomes (as measured by final grades) and greater student satisfaction (for a review, see Cho \& Kim, 2013). In looking at this literature from a constructivist perspective, it is useful to adapt a distinction that Chapman (2003) made for face-to-face learning, between activity-as-participation - for instance, attending class and submitting assignments - and activity-as-interaction - the sustained involvement in learning activities involving cognitive, behavioural, and affective aspects. In face-to-face classrooms, activity-as-participation is measured in a number of ways, including attendance, number of homework or other assignments submitted, and time on task. In online courses, the most easily accessible counterparts to these measures are a combination of frequency and duration variables (Morris, Finnegan, \& Wu, 2005): number of logins, number of pages accessed, number of assignments submitted, time spent in the system, etc. In what follows, we will call these attendance variables. For the online counterparts to classroom interaction, the most accessible and frequently used LMS variables are discussion forum posts viewed and discussion forum posts authored. In what follows, we will call these interactivity behaviours. Taken together, these become a measure of overall student engagement. 
(2015). Exploring the link between online behaviours and course performance in asynchronous online high school courses. Journal of Learning Analytics, 2(2), 169-194. http://dx.doi.org/10.18608/jla.2015.22.13

As researchers have searched for behaviours associated with success, the kinds of activity they have analyzed have differed, as have their results. A number of studies have found that only attendance behaviours are correlated with final grades. For example, in higher education Wang and Newlin (2000) looked at homepage hits, posts read, and posts written for 51 students in three sections of a Psychology course. They found that the one frequency behaviour - homepage hits - alone predicted student grades. Similarly, Ramos and Yudko (2008), examining the same three variables, found that page hits was the only variable that had a positive relationship with final grades. On the other hand, Ryabov (2012), looking at 286 students in online introductory sociology courses at one university, found that only the duration behaviour of time spent was significant.

Other studies have found that interactivity behaviours were also important. For example, Hung and Zhang (2008), looking at 98 students in an undergraduate business course, found that participation in online discussions had a stronger correlation with performance than accessing course materials. Wei, Peng, and Chou (2015), looking at 381 undergraduates in a general education course, found that number of discussion board postings and frequency of viewing reading materials, along with frequency of logins, were positively correlated with final exam scores. Macfadyen and Dawson (2010), using data from 118 students in five different biology courses, found that it was number of messages posted, number of email messages sent, and number of assessments completed that had positive correlations with final grades. Morris, Finnegan, and Wu (2005), looking at over 423 students in three undergraduate education courses, found that it was discussion posts viewed, as well as content pages viewed and time spent viewing discussions, that had positive correlations with final grades. Similarly, Dawson, McWilliam, and Tan (2008), looking at a 1,000-student undergraduate science class, found that more time spent online and more participation in discussions were associated with higher final grades. In contrast, Davies and Graff (2005), looking at 122 students over the course of a year, found no relationship between discussion forum activity and final grades.

To date, there have been very few studies using LMS data at the high school level. While the research in higher education has often focused on one or two classes or a single subject, the high school studies have looked at large numbers of students across many subjects; this adds subject area as a complicating factor. Thus Liu and Cavanaugh (2011b, 2012), using data for the 2007-2008 academic year at one staterun online high school, looked at eight possible predictors of end-of-course exam results for two biology and four algebra courses, with a total of 662 students. The predictors included one frequency variable (number of logins) and one duration measure (total minutes spent in the system) but no measures of student-student interaction (presumably because these were self-paced courses). They found a mixed picture: number of logins was not correlated with final grades for the two biology courses but was correlated for three of the four algebra courses, while time spent logged in was correlated with final grades for both biology courses and three of the four algebra courses. Further, when they examined a wider range of 15 courses, with a total of 1,794 students, they found that number of logins was correlated with final grades in only three of the 12 courses but time spent logged in was significant in 11 (Liu \& Cavanaugh, 2011a). 
(2015). Exploring the link between online behaviours and course performance in asynchronous online high school courses. Journal of Learning Analytics, 2(2), 169-194. http://dx.doi.org/10.18608/jla.2015.22.13

While Liu and Cavanaugh looked at three behaviours, Hung, Hsu, and Rice (2012) looked at seven, using data from approximately 7,000 students at a statewide online school for the 2009-2010 academic year. Most of the behaviours were frequency behaviours (clicks, course content accessed, course access, page access, tab access, module access), with only one related to student-student interaction (number of discussion board posts) and none related to duration. They found a positive relationship between all these behaviours and performance, although there were variations from course to course, depending on subject area and on course level.

All of these findings suggest that there is indeed a link between student activity and outcomes as measured by final grades. However, the behaviours chosen for analysis have varied, in part depending on what is available from the LMS and in part on which behaviours each researcher feels are important. In addition, most have used first-generation statistical techniques for their data analysis (i.e., Pearson's correlations, multiple regression, hierarchical linear modelling, decision tree and cluster analysis), which only allow the investigation of a single layer of the relationship(s) between the explanatory variable(s) (i.e., the behaviours) and the outcome variable (course grade). We hoped that we could overcome the limitations in previous studies by building models that hypothesize multiple layers of relationships and test these interrelationships at one time using structural equation modelling (SEM), a family of methods that are second-generation statistical techniques. For instance, since all of the literature suggests a link between online behaviours and learning outcomes, we could explore whether such behaviours can be explained by a latent construct that cannot otherwise be directly measured. In addition, one important advantage of SEM is its ability to explicitly estimate the unreliability of the observed variables (i.e., measurement error), whereas standard linear regression modelling assumes that variables are observed without error (Bollen \& Long, 1993; Gerow, Grover, Roberts, \& Thatcher, 2010; Kline, 2011).

Although only a few researchers have considered whether there are gender differences in LMS behaviours, their findings suggest that male and female students may approach online learning differently, with different degrees and styles of participation (Yukselturk \& Bulut, 2009; Rovai, 2001). For example, McSporran and Young (2001), analyzing data from a college-level web design course, found that women showed consistently higher levels of activity than males in their online classes, completed more assignments, seemed to be better at self-regulation, and performed better. Similarly, Hung, Hsu, and Rice (2012) also found that females performed better and were more active than males. Johnson (2011), analyzing data from a large information systems course, found that females' higher levels of interaction and general sociability were an advantage in online courses and likely to lead to better outcomes for females than males. We therefore felt that it was important to explore the role of gender in our analysis.

\section{RESEARCH QUESTIONS}

While some of the researchers cited above found that only the attendance behaviours were significantly correlated with final grades, others found that interactivity behaviours were important as well. For 
(2015). Exploring the link between online behaviours and course performance in asynchronous online high school courses. Journal of Learning Analytics, 2(2), 169-194. http://dx.doi.org/10.18608/jla.2015.22.13

those who believe that student-student interaction is critical for learning, both types of activity should show such a relationship. Desire2Learn, PJE's LMS, provided us with a limited number of behaviours. These included three attendance behaviours - number of days accessed, number of logins, and time spent logged in - and two interactivity behaviours - posts viewed and posts authored. Using this data, we addressed the following questions:

RQ1: Is there a relationship between the students' course behaviours and their course performance? RQ2: Is there a relationship between the students' course behaviours, when grouped into attendance and interactivity behaviours, and their course performance?

RQ3: Should gender be taken into consideration in the analysis of course behaviours and course performance?

\section{THE RESEARCH SITE}

Our study setting was the 12 asynchronous online courses offered by Pamoja Education (PJE), the course provider for the International Baccalaureate (IB), in 2013-2014. The courses were online, fully asynchronous, and follow a cohort-paced weekly schedule, similar to most online courses in higher education. Some courses had only one section, while others had as many as six, for a total of 39 sections, with approximately 20 students per section and a total of 798 students. Most of the students were taking these courses as part of the IB Diploma, a challenging program for students in their last two years of high school, but some were taking them as single courses. All of the courses lasted two years. They included Business Management, Economics, Film, Information Technology in a Global Society, Mathematics, Philosophy, Psychology, Mandarin, and Spanish. The students not only completed readings, wrote essays, and submitted other assignments but were expected to interact with each other in structured, facilitated discussion forums and to engage in multi-week group projects. Discussion forum posts were not graded but discussion forum participation was part of the course evaluation rubric and in that way became part of the final grade.

\section{COURSE BEHAVIOURS AND COURSE PERFORMANCE: EXPLORATORY ANALYSIS}

\subsection{Course Performance}

The sample began with the entire cohort of 798 students in the first year of their courses. The gender makeup was $55 \%$ female $(n=439)$ and $45 \%$ male $(n=359)$. In the IB system, grades are numeric, not alphabetical, and range from 1 to 7 , with 4 to 7 considered passing grades. Of the 798 students enrolled as of the second week of the academic year (chosen as the beginning point because students were still enrolling in week 1), 689 received a year-end grade, with most of those who dropped doing so within the grace period (i.e., without penalty). As Table 1 shows, $21 \%$ of the students were not passing at the end of the fall semester and $23 \%$ at year-end: 
(2015). Exploring the link between online behaviours and course performance in asynchronous online high school courses. Journal of Learning Analytics, 2(2), 169-194. http://dx.doi.org/10.18608/jla.2015.22.13

Table 1. Percentage receiving each grade

\begin{tabular}{|c|c|c|c|c|}
\hline \multirow[b]{2}{*}{ Final grade } & \multicolumn{2}{|c|}{ End of fall semester } & \multicolumn{2}{|c|}{ End of academic year } \\
\hline & Count & Percent & Count & Percent \\
\hline 7 & 143 & $18 \%$ & 96 & $14 \%$ \\
\hline 6 & 194 & $24 \%$ & 143 & $21 \%$ \\
\hline 5 & 175 & $22 \%$ & 151 & $22 \%$ \\
\hline 4 & 115 & $15 \%$ & 143 & $21 \%$ \\
\hline $1-3$ & 166 & $21 \%$ & 156 & $23 \%$ \\
\hline Total & 793 & $100 \%$ & 689 & $100 \%$ \\
\hline
\end{tabular}

In addition, as is common at the high school level (Voyer \& Voyer, 2014), females on average had higher grades than males at both points in time, and a higher percentage of females than males received the highest grade of 7 (Table 2).

Table 2. Percentage of passing students by grade category by gender

\begin{tabular}{lcccccc}
\hline & \multicolumn{3}{c}{ End of fall semester } & \multicolumn{3}{c}{ End of academic year } \\
& Mean grade & $\begin{array}{c}\text { \% passed } \\
(4-7)\end{array}$ & \% with 7 & Mean grade & $\begin{array}{c}\text { \% passed } \\
(4-7)\end{array}$ & \% with 7 \\
\hline Female & 5.1 & $85 \%$ & $23 \%$ & 4.9 & $81 \%$ & $20 \%$ \\
Male & 4.5 & $72 \%$ & $12 \%$ & 4.4 & $74 \%$ & $7 \%$ \\
\hline
\end{tabular}

\subsection{Descriptive Statistics of Course Behaviours}

The LMS output came to us as data for each student cumulated for each week that he or she was enrolled. PJE also provided us with final grades.

As noted above, the LMS behaviours related to attendance were:

- \# days: The number of days a student accessed the system;

- \# logins: The number of times a student logged into the system;

- Session duration: The total hours a student spent logged in ${ }^{1}$.

The LMS behaviours related to interactivity were:

- Posts viewed: The number of posts a student viewed.

- Posts authored: The number of posts a student wrote.

Table 3 gives the means for these behaviours for the 689 students who completed the year. When the weekly LMS behaviours are totalled and then averaged over the 32 weeks, we see that students logged in between 3 and 4 days a week and spent about half an hour per login. As would be expected, they viewed many more posts than they authored. However, females were more active than males for all

\footnotetext{
1 Session duration was the amount of time from login to logout. If the student did not deliberately log out, the system logged them out after 20 minutes. This figure may therefore be a slight overestimate.
} 
(2015). Exploring the link between online behaviours and course performance in asynchronous online high school courses. Journal of Learning Analytics, 2(2), 169-194. http://dx.doi.org/10.18608/jla.2015.22.13

behaviours. This was the first hint that, as suggested by other research, there are gender differences in online behaviours (Hung, Hsu, \& Rice, 2012; Lowes \& Lin, 2015).

Table 3. Mean course behaviours, all weeks (2-33)

\begin{tabular}{lccccc}
\hline & \# days & \# logins & $\begin{array}{c}\text { Time spent } \\
\text { (\# hours) }\end{array}$ & $\begin{array}{c}\text { \# posts } \\
\text { viewed }\end{array}$ & $\begin{array}{c}\text { \# posts } \\
\text { authored }\end{array}$ \\
\hline All & 3.6 & 8.0 & 5.2 & 14.5 & 1.5 \\
Female & 3.8 & 8.7 & 5.4 & 15.8 & 1.6 \\
Male & 3.4 & 7.2 & 4.9 & 13.0 & 1.4 \\
\hline
\end{tabular}

The differences between males and females were greatest for number of logins and number of posts viewed (Figure 1).

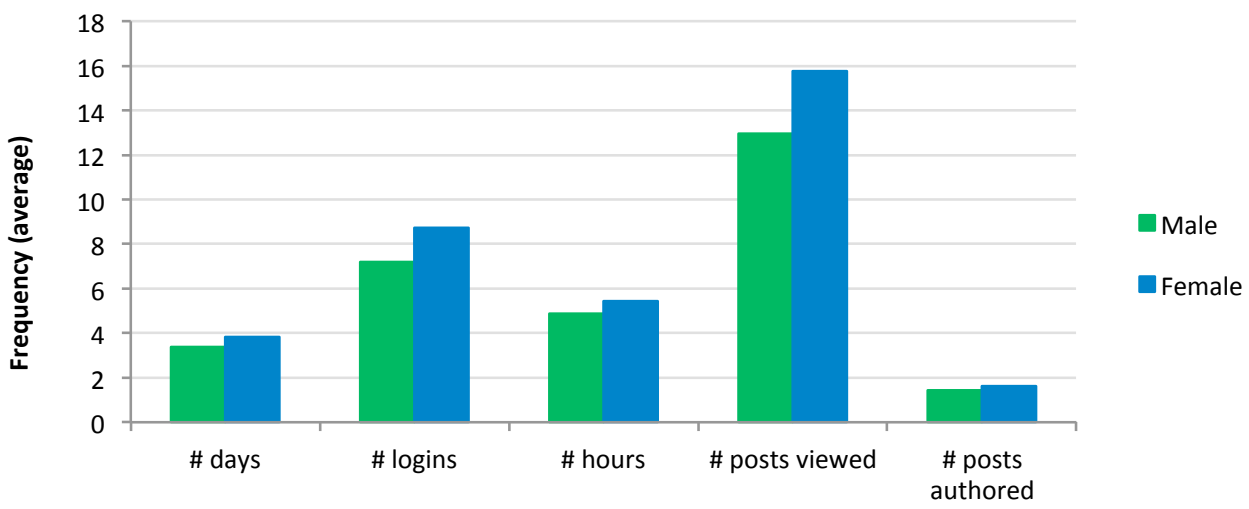

Figure 1. Mean course behaviours by gender

However, there was a wide range for all behaviours and for both genders (Table 4).

Table 4. Range for course behaviours, all weeks (2-33)

\begin{tabular}{lccccc}
\hline & \# days & \# logins & $\begin{array}{c}\text { Time spent } \\
\text { (\# hours) }\end{array}$ & $\begin{array}{c}\text { \# posts } \\
\text { viewed }\end{array}$ & $\begin{array}{c}\text { \# posts } \\
\text { authored }\end{array}$ \\
\hline All & $0.0-6.7$ & $0.0-34.1$ & $0.0-18.8$ & $0.0-69.3$ & $0.0-8.9$ \\
Female & $0.4-6.7$ & $0.4-34.1$ & $0.2-18.8$ & $0.0-68.5$ & $0.0-8.9$ \\
Male & $0.0-6.5$ & $0.0-24.5$ & $0.0-17.1$ & $0.0-69.3$ & $0.0-6.6$ \\
\hline
\end{tabular}

In addition, the means obscure a skewed distribution for all behaviours but number of days. Figure 2 shows the raw counts for weeks $2-33$ combined. This posed a problem for analysis that we dealt with by using a robust estimator. ${ }^{2}$

\footnotetext{
2 Due to the violations of normality assumption for each behaviour as well as the multivariate normality assumption $(p<.001$
} for all), WLSMV was selected for the confirmatory factor analysis later as it is robust to non-normality. 
(2015). Exploring the link between online behaviours and course performance in asynchronous online high school courses. Journal of Learning Analytics, 2(2), 169-194. http://dx.doi.org/10.18608/jla.2015.22.13
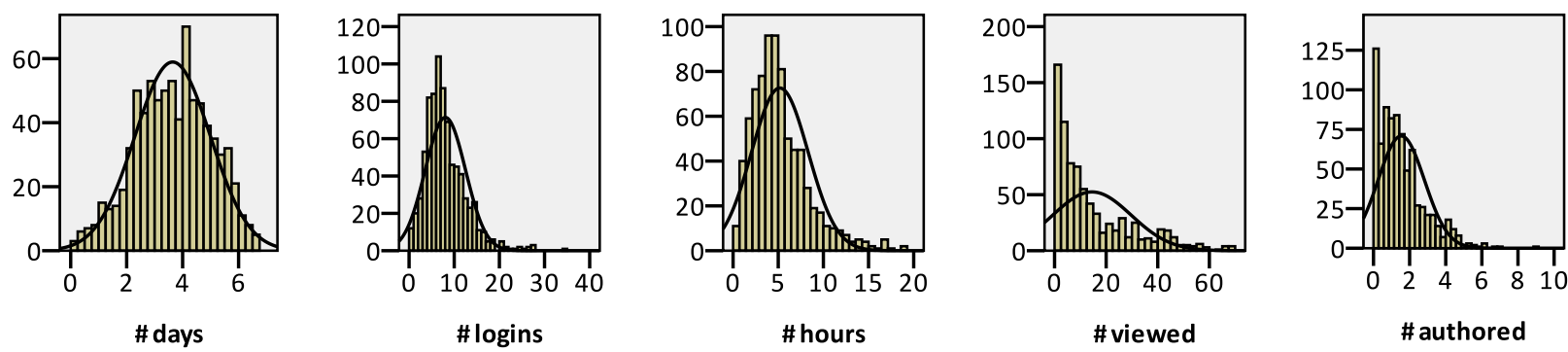

Figure 2. Frequencies for each behaviour

Looked at over time, gender differences held for all three attendance behaviours for all but a few of the final weeks (Figure 3). Note that week 25 was a break week.

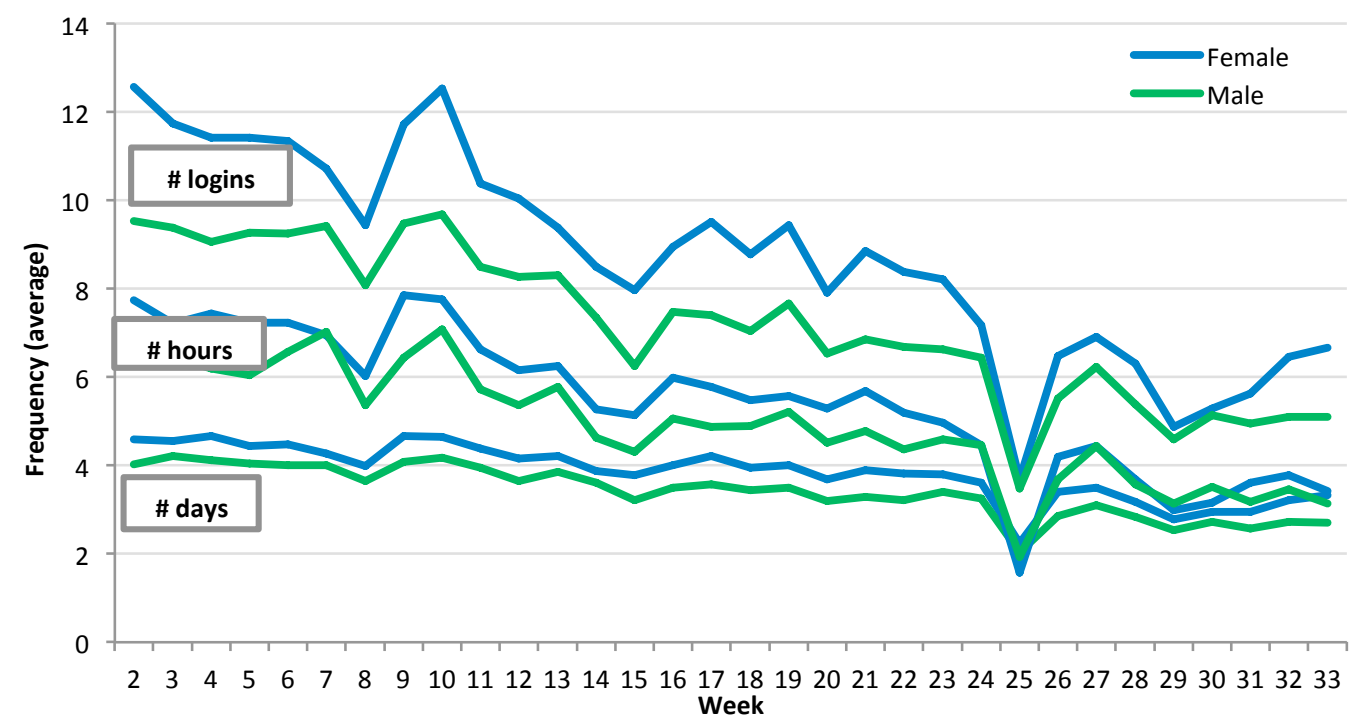

Figure 3. Mean course attendance behaviours by gender, all weeks

The gender differences also held for both interactivity variables, with females both viewing and authoring more posts in almost every week (Figure 4). 
(2015). Exploring the link between online behaviours and course performance in asynchronous online high school courses. Journal of Learning Analytics, 2(2), 169-194. http://dx.doi.org/10.18608/jla.2015.22.13



Figure 4. Mean course interactivity behaviours by gender, all weeks

Overall, this data suggested that there were differences in the behaviour of males and females, with females being more active than males for both the attendance and the interactivity behaviours.

\subsection{Bivariate Correlations of Course Behaviours}

Table 5 summarizes the linear correlations between pairs of behaviours. It shows that all behaviours are correlated with one another $(p<.001)$ but that the correlations are stronger among the three attendance behaviours, and between the two interactivity behaviours, than between any one of the three attendance behaviours and either of the two interactivity behaviours. The fact that this held true for all students and for both genders suggested that two types of behaviour are indeed present.

Table 5. Linear correlations between course behaviours for all students, females, and males

\begin{tabular}{|c|c|c|c|c|c|}
\hline \multirow[b]{2}{*}{ All $(N=798)$} & \multicolumn{3}{|c|}{ Attendance behaviour } & \multicolumn{2}{|c|}{ Interactivity behaviour } \\
\hline & \# days & \# logins & \# hours & \# viewed & \# authored \\
\hline \# days & - & & & & \\
\hline \# logins & $.857 * * *$ & - & & & \\
\hline \# hours & $.713 * * *$ & $.685 * * *$ & - & & \\
\hline \# posts viewed & $.501 * * *$ & $.435 * * *$ & $.370 * * *$ & - & \\
\hline \# posts authored & $.562 * * *$ & $.496 * * *$ & $.465 * * *$ & $.740 * * *$ & - \\
\hline Females $(n=439)$ & \# days & \# logins & \# hours & \# viewed & \# authored \\
\hline \# days & - & & & & \\
\hline \# logins & $.838 * * *$ & - & & & \\
\hline \# hours & $.707 * * *$ & $.700 * * *$ & - & & \\
\hline \# posts viewed & $.485 * * *$ & $.398 * * *$ & $.375^{* * *}$ & - & \\
\hline \# posts authored & $.552 * * *$ & $.480 * * *$ & $.487 * * *$ & $.716 * * *$ & - \\
\hline
\end{tabular}


(2015). Exploring the link between online behaviours and course performance in asynchronous online high school courses. Journal of Learning Analytics, 2(2), 169-194. http://dx.doi.org/10.18608/jla.2015.22.13

\begin{tabular}{lccccc}
\hline Males $(n=359)$ & \# days & \# logins & \# hours & \# viewed & \# authored \\
\hline \# days & - & & & & \\
\# logins & $.886^{* * *}$ & - & & \\
\# hours & $.716^{* * *}$ & $.667^{* * *}$ & - & \\
\# posts viewed & $.509 * * *$ & $.481^{* * *}$ & $.355^{* * *}$ & - & \\
\# posts authored & $.570^{* * *}$ & $.520^{* * *}$ & $.433^{* * *}$ & $.765^{* * *}$ & - \\
\hline
\end{tabular}

Note: $* * *<.001$.

\subsection{Course Behaviours and Final Grades}

When we look at course behaviours by final grade (Table 6), we see that higher grades are associated with higher mean course behaviours (i.e., with each behaviour averaged over the 32 weeks). We also see that students who did not pass their courses (grades of 1-3) were far less active than students who did (grades of 4-7), no matter which behaviour is considered.

Table 6. Final grades with mean behaviours.

\begin{tabular}{lccccc}
\hline Final grade & \# days & \# logins & $\begin{array}{c}\text { Time spent } \\
\text { (\# hours) }\end{array}$ & $\begin{array}{c}\text { \# posts } \\
\text { viewed }\end{array}$ & $\begin{array}{c}\text { \# posts } \\
\text { authored }\end{array}$ \\
\hline 7 & 4.6 & 11.0 & 6.8 & 17.9 & 2.2 \\
6 & 4.4 & 9.8 & 6.5 & 18.6 & 2.1 \\
5 & 4.0 & 8.6 & 5.5 & 19.7 & 1.9 \\
4 & 3.5 & 7.5 & 5.0 & 14.0 & 1.5 \\
$1-3$ & 2.8 & 5.9 & 3.7 & 8.0 & 0.9 \\
\hline
\end{tabular}

Table 7 shows that this was the case for both genders.

Table 7. Final grades with mean behaviours by gender.

\begin{tabular}{ccccccc}
\hline & $\begin{array}{c}\text { Final } \\
\text { grade }\end{array}$ & \# days & \# logins & Time spent & $\begin{array}{c}\text { \# posts } \\
\text { viewed }\end{array}$ & $\begin{array}{c}\text { \# posts } \\
\text { authored }\end{array}$ \\
\hline Female & 7 & 4.6 & 11.3 & 6.6 & 17.4 & 2.1 \\
& 6 & 4.5 & 10.2 & 6.8 & 19.5 & 2.1 \\
& 5 & 4.2 & 9.4 & 5.8 & 20.2 & 1.9 \\
& 4 & 3.7 & 8.1 & 5.1 & 15.1 & 1.5 \\
Male & $1-3$ & 3.0 & 6.5 & 3.8 & 10.3 & 1.0 \\
& 7 & 4.5 & 10.0 & 7.6 & 19.8 & 2.6 \\
& 6 & 4.3 & 9.4 & 6.3 & 17.7 & 2.1 \\
& 5 & 3.7 & 7.5 & 5.0 & 19.0 & 1.9 \\
& 4 & 3.3 & 7.0 & 4.8 & 12.9 & 1.4 \\
\hline
\end{tabular}

The difference is particularly evident when we compare the behaviours of passing and not-passing students (Figure 5). The largest difference is in the interactivity behaviour of posts viewed. 
(2015). Exploring the link between online behaviours and course performance in asynchronous online high school courses. Journal of Learning Analytics, 2(2), 169-194. http://dx.doi.org/10.18608/jla.2015.22.13

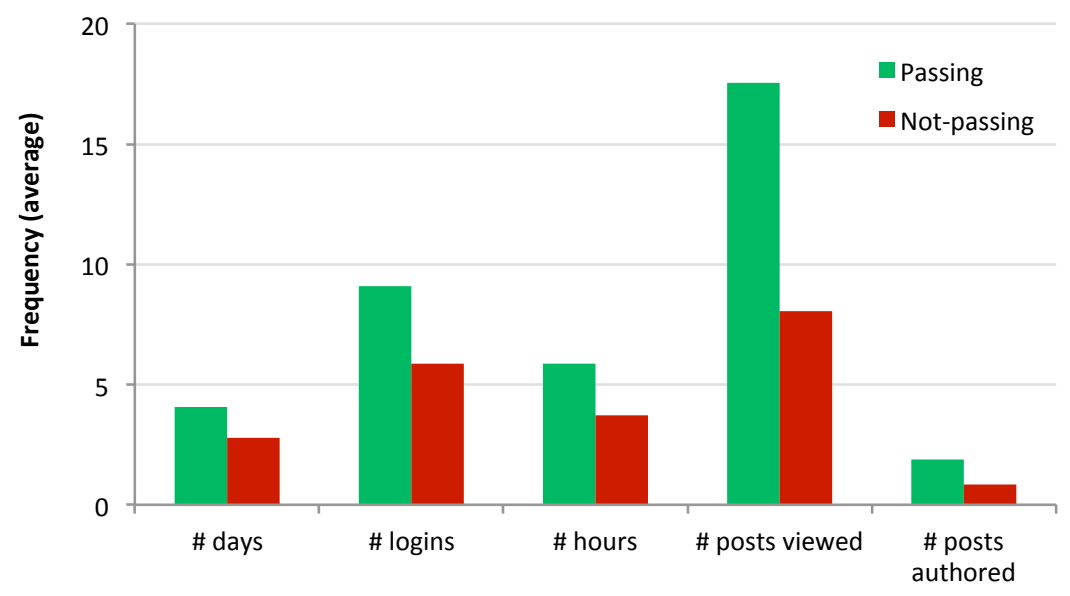

Figure 5. Mean course behaviours, passing and not-passing students

Figure 6 shows that this difference holds true for both genders. It also shows that, while passing males and females viewed similar numbers of posts, females who were not passing were more active in viewing posts than males who were not passing.

Females

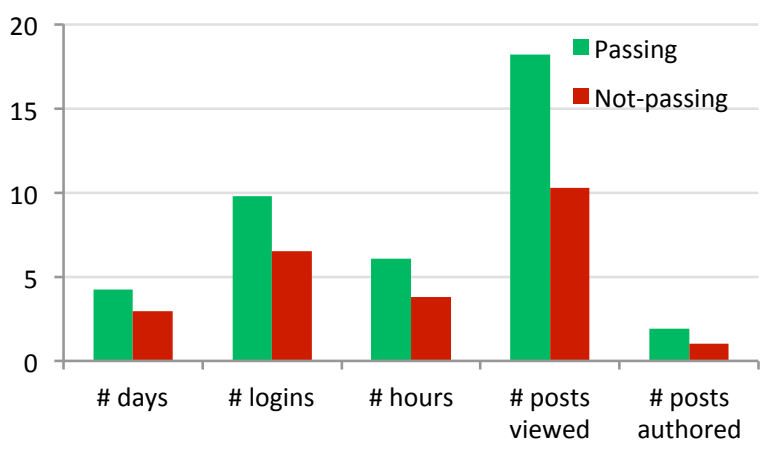

Males

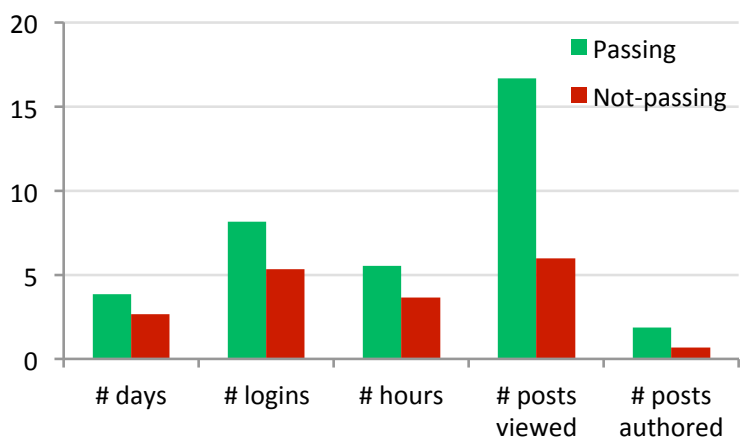

Figure 6. Mean course behaviours, passing and not-passing students, by gender

Table 8 summarizes the linear correlations. These provide statistical evidence that all five behaviours are correlated with final grades ( $p<.001$ for all), but that the interactivity behaviours are not as strongly correlated as the attendance behaviours. This is not surprising given that not all courses emphasize interaction to the same extent and that some types of interaction are not captured by post-related behaviours. However, the strengths of the correlations with final grades are consistently larger for males than females; this is particularly the case with the interactivity behaviours. 
(2015). Exploring the link between online behaviours and course performance in asynchronous online high school courses. Journal of Learning Analytics, 2(2), 169-194. http://dx.doi.org/10.18608/jla.2015.22.13

Table 8. Linear correlations between each course behaviour and final grade

\begin{tabular}{lccccc}
\hline & \multicolumn{2}{c}{ Attendance behaviour } & \multicolumn{2}{c}{ Interactivity behaviour } \\
& \# days & \# logins & Time spent & $\begin{array}{c}\text { \# posts } \\
\text { viewed }\end{array}$ & $\begin{array}{c}\text { \# posts } \\
\text { authored }\end{array}$ \\
\hline All & $.565^{* * *}$ & $.440^{* * *}$ & $.390^{* * *}$ & $.244^{* * *}$ & $.365^{* * *}$ \\
Female & $.517^{* * *}$ & $.387^{* * *}$ & $.355^{* * *}$ & $.172^{* *}$ & $.287^{* * *}$ \\
Male & $.591^{* * *}$ & $.474^{* * *}$ & $.416^{* * *}$ & $.312^{* * *}$ & $.454^{* * *}$ \\
\hline Note: $* * p<01, * * * p<.001$ & & & &
\end{tabular}

In other words, the level of activity explains less about female performance than male performance. In addition, the weak correlations between both posts viewed and post authored and final grades for females suggests that higher levels of activity in these two behaviours in particular do not translate into higher grades.

\subsection{Summary of Exploratory Analysis}

This exploratory analysis provides preliminary insights into the relationships among course behaviours and between course behaviours and course performance. First, for all behaviours, higher levels of activity are associated with higher grades. Second, the correlations among the three attendance behaviours and between the two interactivity behaviours suggest that two types of behaviour are present. However, while higher levels of activity for both types of behaviour are associated with higher final grades, the correlations between each interactivity behaviour and final grades are lower than the correlations between each attendance behaviour and final grades. Third, the existence of gender differences - females were more active than males for all behaviours but the strength of the correlations between each behaviour and final grades was higher for males than females - suggests that gender needs to be taken into consideration in any further exploration of the relationship between course behaviours and course performance.

\section{COURSE BEHAVIOURS AND COURSE PERFORMANCE: STATISTICAL MODELS}

We next wanted to explore whether multiple behaviours taken together can tell us more about the relationships between the behaviours and course performance than any single behaviour can. Since the five behaviour variables were measured on different scales and the sample variances exceeded 1 to 10 , which led to convergence problems, the five behavioural variables were standardized to have a mean of 0 and a standard deviation of 1 . 
(2015). Exploring the link between online behaviours and course performance in asynchronous online high school courses. Journal of Learning Analytics, 2(2), 169-194. http://dx.doi.org/10.18608/jla.2015.22.13

\subsection{Exploring Course Behaviours}

As the first step, we hypothesized that the five observed behaviours share a common domain that can be explained by an unobserved latent factor that we will call course engagement. Figure 7 shows the conceptual model, with E indicating allowance for measurement error:

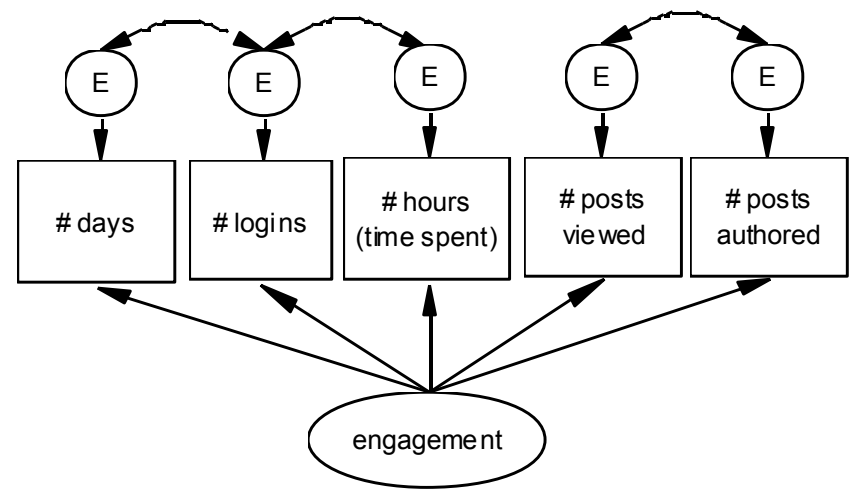

Figure 7. Conceptual model of course engagement

To investigate this, we first performed confirmatory factor analysis (CFA) using Mplus 7.1 (Muthén \& Muthén, 2013). ${ }^{3}$ CFA Model 1 examines course engagement for all students. The model fit indices show that the model fits the data well (see Appendix, Table 1, for all CFA model fit indices). Figure 8 shows the standardized factor loadings and coefficients for this model. It provides statistical evidence that the latent factor, engagement, explains all five LMS behavioural variables $\left(p<.001\right.$ for all). ${ }^{4}$

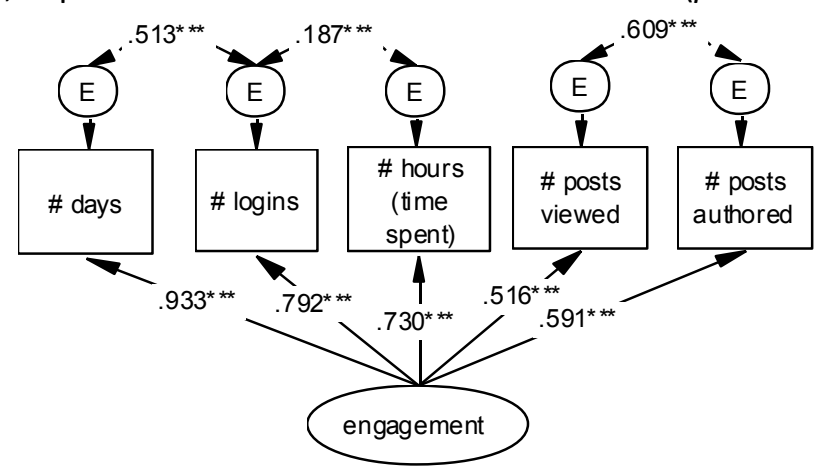

Figure 8. Standardized parameter estimates for CFA Model 1

While CFA Model 1 is a good model fit, it does not allow us to examine the role of gender. To do this, we ran the separate analyses for females (CFA Model 1a) and males (CFA Model 1b). However, although both models fit the data well, this introduced the chance of making a Type 1 error so we then looked at

\footnotetext{
${ }^{3}$ Since the nature of LMS data is limited in the sense that each variable may not be measured independently (for example, number of days accessed and number of logins could be somewhat inclusive), this may lead to correlated errors (variance that is unexplained) among the variables. To deal with this, the model specification included three freely estimated relationships between \# days and \# logins, \# logins and \# hours (time spent), and \# posts viewed and \# posts authored (without freeing the relationship between \# days and \# hours). Note that correlated variables are linked by curved lines.

${ }^{4}$ For unstandardized factor loadings and coefficients for all the analyses, please contact the corresponding author.
} 
(2015). Exploring the link between online behaviours and course performance in asynchronous online high school courses. Journal of Learning Analytics, 2(2), 169-194. http://dx.doi.org/10.18608/jla.2015.22.13

all students with gender considered as a grouping variable (CFA Model 2). Once again, it was a good model fit. Figure 9 shows the standardized factor loadings and coefficients for this model. It provides statistical evidence that the latent factor engagement explains all five LMS behaviour variables for both females and males when they are included in the same model ( $p<.001$ for all).
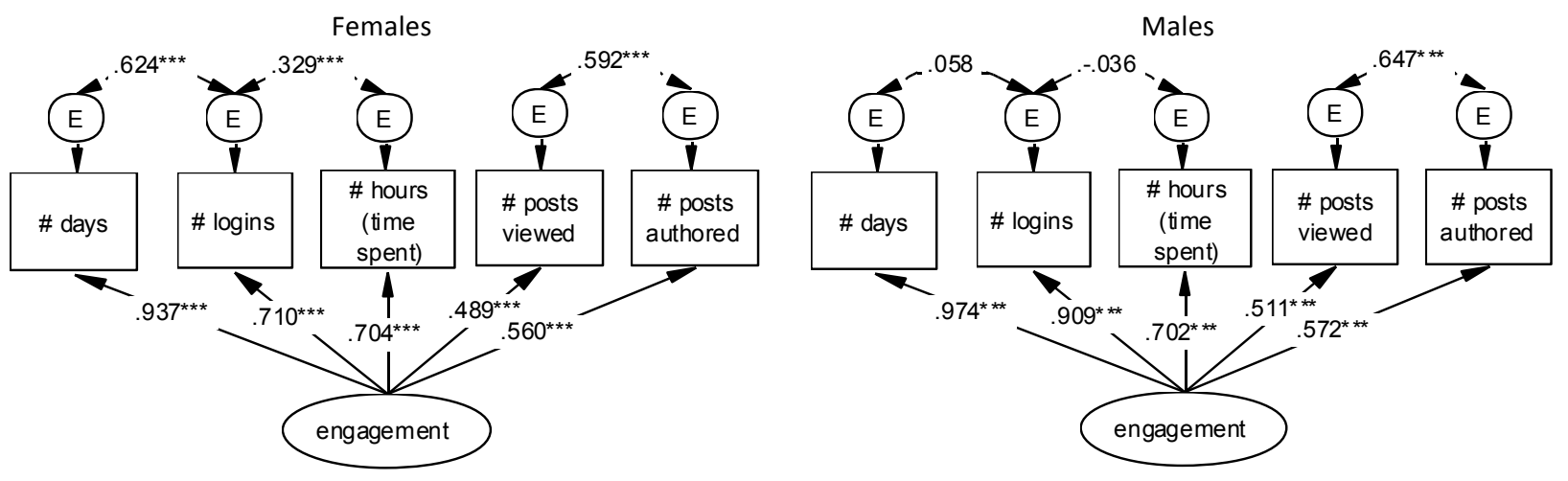

Figure 9. Standardized parameter estimates for CFA Model 2

Although both CFA Model 1 and CFA Model 2 are helpful in explaining the relationship between engagement and the behavioural variables, we wanted to know if the proportion of variance explained in the behaviours by the latent factor engagement differed for the two models. Table 9 compares the $R$ squared information.

Table 9. $\boldsymbol{R}$-squared information for CFA Models 1 and 2

\begin{tabular}{lcccccc}
\hline Model & Gender & \# days & \# logins & $\begin{array}{c}\text { \# hours } \\
\text { (time spent) }\end{array}$ & $\begin{array}{c}\text { \# posts } \\
\text { viewed }\end{array}$ & $\begin{array}{c}\text { \# posts } \\
\text { authored }\end{array}$ \\
\hline CFA Model 1 & Not considered & .871 & .627 & .532 & .266 & .349 \\
CFA Model 2 & Females & .879 & .505 & .495 & .239 & .314 \\
CFA Model 2 & Males & .948 & .827 & .493 & .261 & .327 \\
\hline
\end{tabular}

The greatest difference between males and females is in the number of logins. CFA Model 1, which does not consider gender, shows that course engagement explains about $63 \%$ of the variance in logins. However, CFA Model 2 shows that course engagement explains much more of the variance in the login behaviour of males $(83 \%)$ than females $(51 \%)$. In other words, taking gender into consideration shows that there are differences between males and females that we would not have seen otherwise. In addition, the latent variable engagement explains more of the attendance behaviours than the interactivity behaviours. 
(2015). Exploring the link between online behaviours and course performance in asynchronous online high school courses. Journal of Learning Analytics, 2(2), 169-194. http://dx.doi.org/10.18608/jla.2015.22.13

\subsection{Exploring the Relationship between Course Behaviours and Final Grades}

The second step was to use structural equation modelling (SEM) to extend CFA Models 1 and 2 in order to examine the relationship between the five behaviours and final grades. ${ }^{5}$ Figure 10 shows the conceptual model.

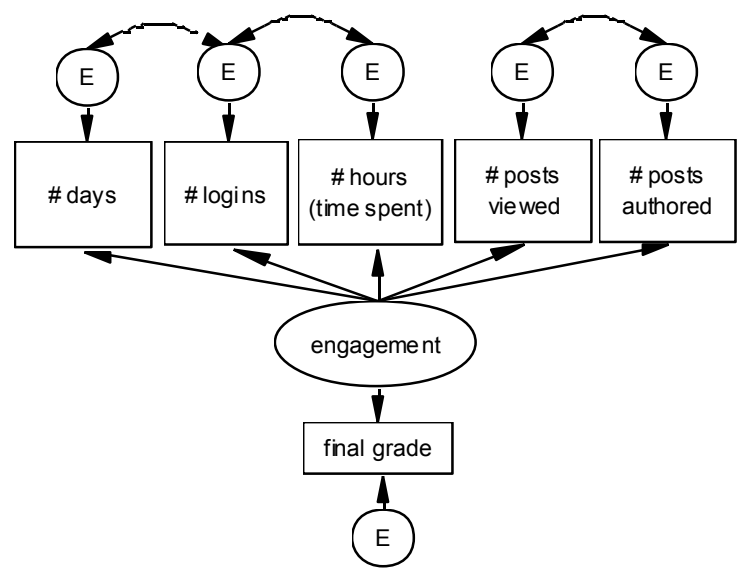

Figure 10. Conceptual model for relationship between engagement and final grade

SEM Model 1 is a good model fit (see Appendix, Table 2, for model fit indices). Figure 11 shows the standardized factor loadings and coefficients for SEM Model 1. It provides statistical evidence that all five behaviours are measured by course engagement $(p<.001$ for all), and that higher levels of engagement increase the predicted probability of higher final grades $\left(\gamma_{11}=.558, p=.000, p<.001\right) .^{6}$ In other words, the model confirms a positive relationship between course behaviours and course performance regardless of gender.

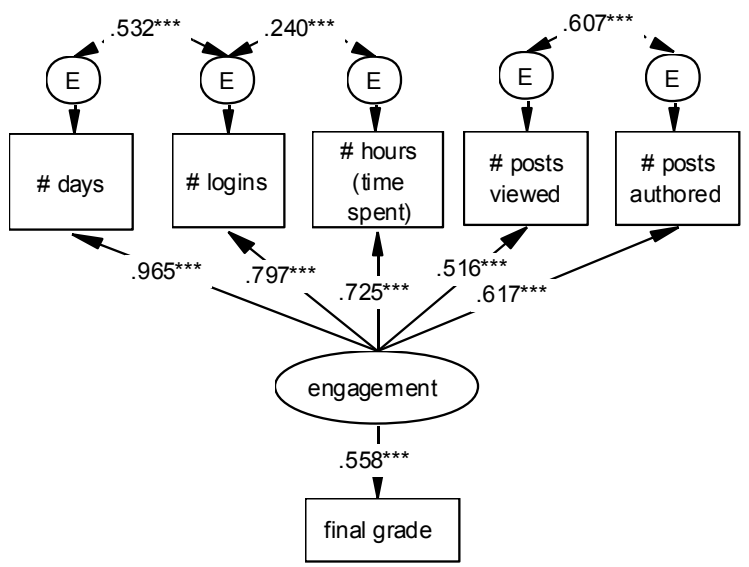

Figure 11. Standardized parameter estimates for SEM Model 1

\footnotetext{
5 We did not consider the approach of multilevel analysis, since being in a different section (total number of sections $=39$ ) only explained about $7 \%$ of the variability in the final grades (analysis performed using HLM 7). The WLSMV estimator was selected for estimation because the outcome variable was categorical and non-normal with a ceiling effect.

${ }^{6}$ Since the final grade was categorical (1-7), we interpret the coefficients as probit regression coefficients.
} 
We next expanded SEM Model 1 to include gender: SEM Model 2 is also a good model fit (see Appendix, Table 2). Figure 12 shows the standardized factor loadings and coefficients for females and males this model. It provides statistical evidence that higher levels of engagement increase the predicted probability of higher final grades for both females $\left(\gamma_{11}=.499, p=.000, p<.001\right)$ and for males $\left(\gamma_{11}=\right.$ .599, $p=.000, p<.001)$. In other words, the model confirms a positive relationship between course behaviours and course outcomes for both females and males. ${ }^{7}$
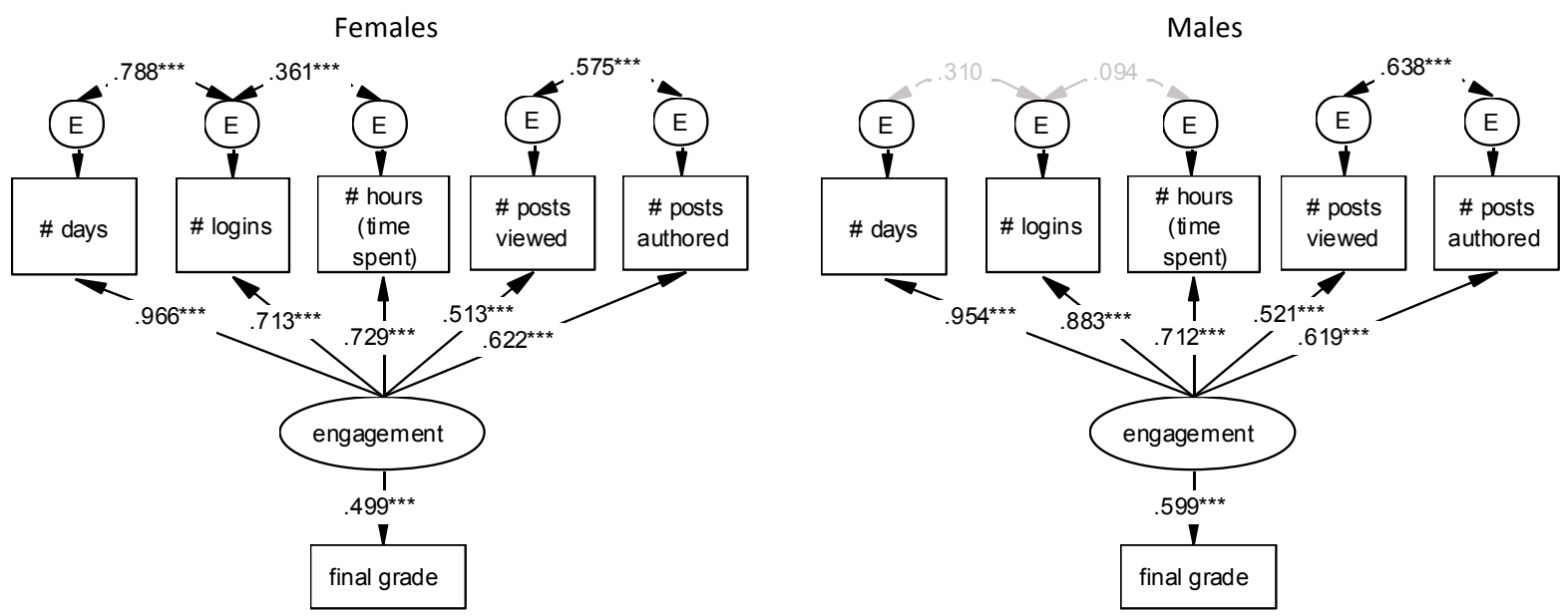

Figure 12. Standardized parameter estimates for SEM Model 2

Table 10 compares the proportion of variance explained by SEM Models 1 and 2 . With gender not considered, SEM Model 1 explains about 31\% of the variance in final grades $\left(R^{2}=.312=.558^{2}\right)$. However, when gender is considered (SEM Model 2), the model explains only $25 \%$ of the variance in the final grades for females $\left(R^{2}=.249=.499^{2}\right)$ but $36 \%$ for males $\left(R^{2}=.359=.599^{2}\right)$.

Table 10. $R$-squared information for SEM Models 1 and 2

\begin{tabular}{lcc}
\hline Model & Gender & $\boldsymbol{R}^{\mathbf{2}}$ \\
\hline SEM 1 & Not considered & .312 \\
SEM 2 & Females & .249 \\
SEM 2 & Males & .359 \\
\hline
\end{tabular}

In other words, course engagement tells us more about the course outcomes for males than females. Although the proportion of variance explained is only medium in a traditional sense (Leech, Barrett, \& Morgan, 2011), it needs to be remembered these engagement behaviours are only part of the larger picture of what a student does while in an online course.

\footnotetext{
7 As an alternative to SEM Model 2, we made gender a fixed factor and formally tested the difference between females and males. This model was also a good model fit. The results confirmed that females had an increased predicted probability of higher engagement $\left(\gamma_{11}=.165, p=.000, p<.001\right)$ and higher final grades $\left(\gamma_{21}=.092, p=.013, p<.05\right)$. (See Appendix, Table 4, for model fit indices, and Appendix, Figure 1, for the conceptual model and parameter estimates.)
} 


\subsection{Exploring the Relationship among Course Behaviours (With Attendance and Interactivity Behaviours Taken Separately) and Final Grades}

Section 6.2 provided statistical confirmation that there is a relationship between the five behaviours (represented by the latent factor engagement) and final grade. However, the exploratory analyses suggested that there also may be two sets of behaviours, attendance and interactivity, that may not have the same relationship to course performance. We therefore built an alternative two-factor model, with and without gender. ${ }^{8}$ Figure 13 shows the conceptual model.

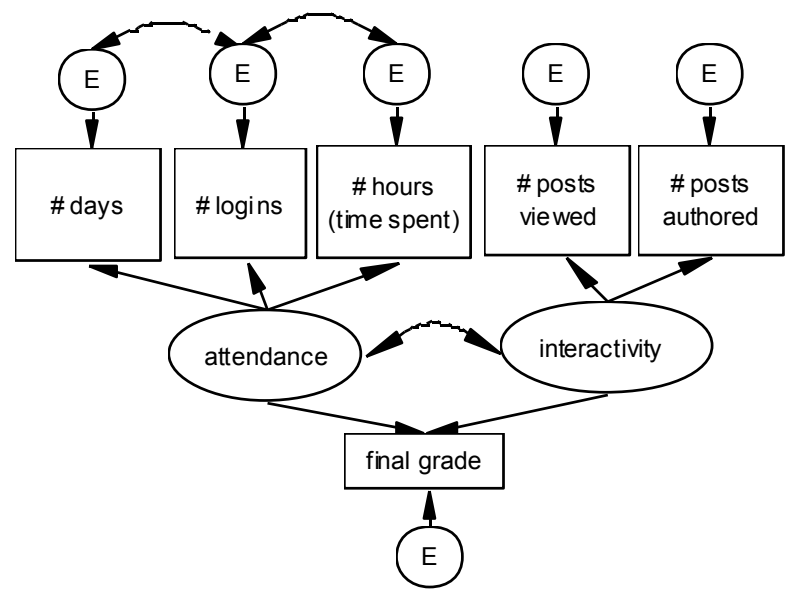

Figure 13. Conceptual model for attendance and interactivity

SEM Model 3 fits the data well (see Appendix, Table 3). Figure 14 shows the standardized factor loadings and coefficients for this model. These provide statistical evidence that number of days accessed, number of logins, and time spent are explained by attendance $(p<.001 \mathrm{for}$ all) and that number of posts viewed and posts authored are explained by interactivity $(p<.001$ for both). However, while there is evidence that higher levels of attendance increase the predicted probability of higher final grades $\left(\gamma_{11}=\right.$ $.538, p=.000, p<.001$ ), there is not sufficient evidence to conclude that higher levels of interactivity do so $\left(\gamma_{12}=.022, p=.682, p>.05\right)$. Thus although we had earlier found a positive relationship between the latent factor engagement and final grades, we now find that when the two aspects of engagement are considered, only attendance behaviours are correlated with final grades.

\footnotetext{
8 As we only had two variables (indicators) for the latent "interactivity" factor, asking to estimate the correlated errors between posts viewed and authored led to model specification issues. Therefore, the correlated errors were not estimated here.
} 
(2015). Exploring the link between online behaviours and course performance in asynchronous online high school courses. Journal of Learning Analytics, 2(2), 169-194. http://dx.doi.org/10.18608/jla.2015.22.13

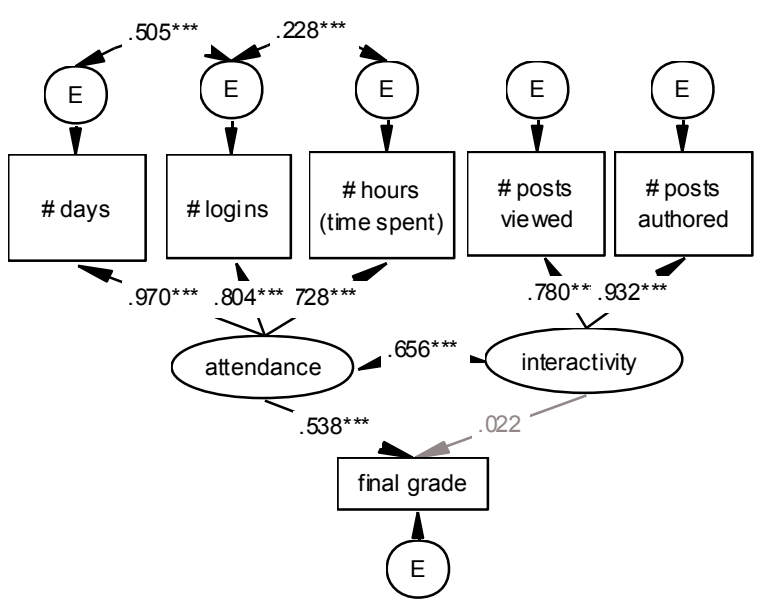

Figure 14. Standardized parameter estimates for SEM Model 3

SEM Model 4 adds in gender and also fits the data well (see Appendix, Table 3). Figure 15 shows the standardized factor loadings and coefficients for females and males for this model. It provides statistical evidence that for males, both higher levels of attendance $\left(\nu_{11}=.447, p=.000, p<.001\right)$ and higher levels of interactivity $\left(\gamma_{12}=.173, p=.007, p<.01\right)$ increase the predicted probability of higher course grades but for females, only higher levels of attendance do so $\left(\gamma_{11}=.588, p=.000, p<.001\right)$. In fact, it suggests that higher levels of interactivity may actually decrease the probability of higher course grades for females, although there is not enough statistical evidence to conclude that this is the case $\left(\gamma_{12}=-.104, p\right.$ $=.226, p>.05)$.
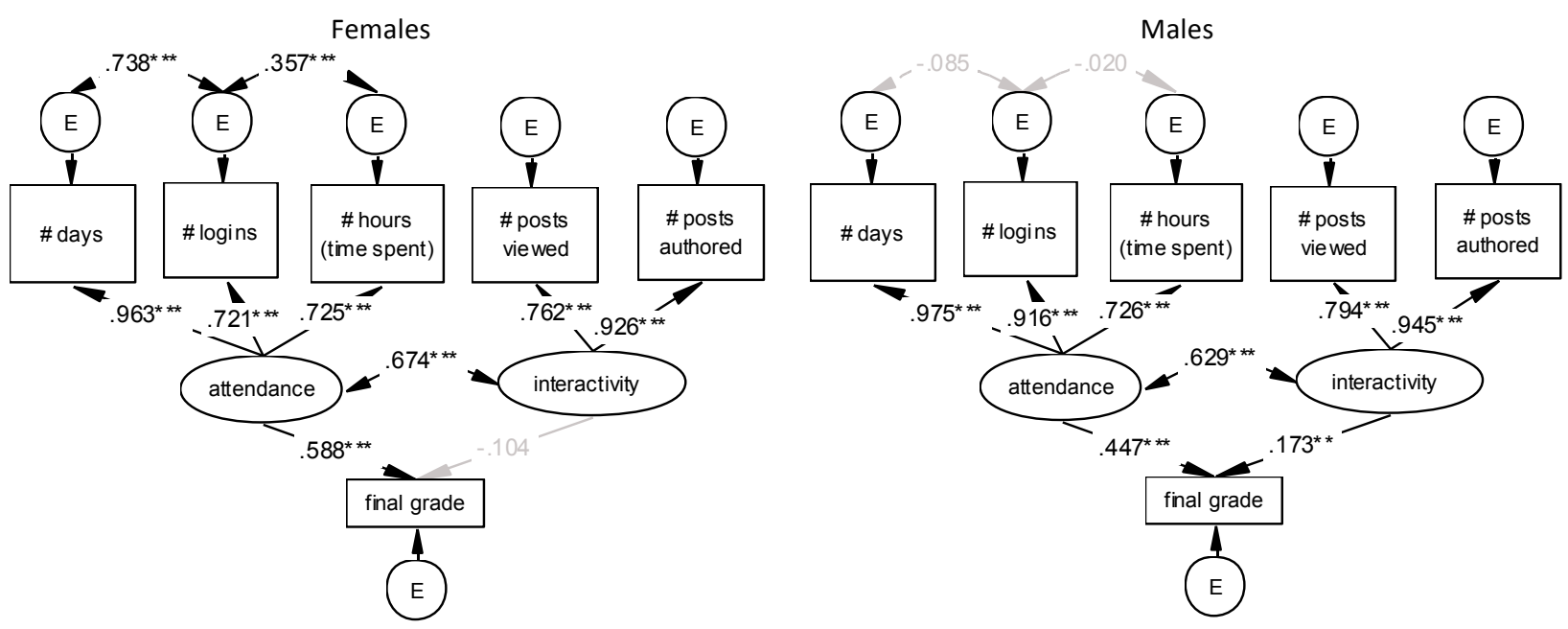

Figure 15. Standardized parameter estimates for SEM Model 4

Table 11 compares the proportion of variance explained by SEM Models 3 and 4 . When gender is not considered, the two-factor model explains about $31 \%$ of the total variance in final grades $\left(R^{2}=.306\right)$. When gender is considered, the model explains $27 \%$ of the variance in the final grades for females $\left(R^{2}=\right.$ $.274)$ and about $33 \%$ for males $\left(R^{2}=.327\right)$ : 
(2015). Exploring the link between online behaviours and course performance in asynchronous online high school courses. Journal of Learning Analytics, 2(2), 169-194. http://dx.doi.org/10.18608/jla.2015.22.13

\begin{tabular}{lcc}
\multicolumn{4}{l}{ Table 11. $\boldsymbol{R}$-squared information for SEM Models $\mathbf{3}$ and $\mathbf{4}$} \\
\hline Model & Gender & $\boldsymbol{R}^{\mathbf{2}}$ \\
\hline SEM Model 3 & Not considered & .306 \\
SEM Model 4 & Females & .274 \\
SEM Model 4 & Males & .327 \\
\hline
\end{tabular}

If we compare the SEM Model 2 and SEM Model 4 (Table 12), both of which consider gender, we see that, although both models fit the data very well, the $R$-squared information suggests that SEM Model 2 , with course engagement as a single factor, explains males' course performance better, but that SEM Model 4, with attendance and interactivity as two separate factors, explains females' course performance better, although the difference between the models for females is less than for males.

Table 12. Comparison of SEM Models 2 and 4

\begin{tabular}{lcc}
\hline & \multicolumn{2}{c}{$\frac{R \text {-squared }}{2}$} \\
Model & Female & Male \\
\hline SEM Model 2 (single-factor) & .249 & .359 \\
SEM Model 4 (two-factor) & .274 & .327 \\
\hline
\end{tabular}

\subsection{Summary of Statistical Models}

The statistical models confirm the relationship between course behaviours and course performance for all students when gender is not considered: Higher levels of all five course behaviours are associated with higher grades. However, when attendance and interactivity behaviours are looked at separately, higher levels of attendance behaviours are associated with higher grades but higher levels of activity behaviours are not.

When gender is considered, higher levels of all five behaviours are correlated with higher grades for both males and females. However, when attendance and interactivity behaviours are looked at separately, higher levels of attendance behaviours are associated with higher grades for both genders but higher levels of interactivity behaviours are associated with higher grades only for males.

\section{$7 \quad$ DISCUSSION}

This research explored the link between course behaviours and final grades in 12 cohort-paced asynchronous online courses for high school students. The LMS provided five behaviours, three of which were considered measures of attendance (number of days accessed, number of logins, and time spent logged in) and two of which were considered measures of student-student interactivity (posts viewed and posts authored). Treating attendance separately from interactivity was important because these courses were designed from a social constructivist perspective, in the belief that students will learn more if they not only engage with the material and with the teacher, but if they engage with each other as well (Jonassen, 1999). In other words, although the course designers believe that both types of 
(2015). Exploring the link between online behaviours and course performance in asynchronous online high school courses. Journal of Learning Analytics, 2(2), 169-194. http://dx.doi.org/10.18608/jla.2015.22.13

engagement are necessary for success, constructivist pedagogy holds that higher levels of studentstudent interactivity are particularly important for better outcomes.

The results of the exploratory analysis and the statistical models show that the five behaviours both analyzed individually and when combined into a latent factor that we called engagement, were positively correlated with final grades (RQ1). In addition, the bivariate correlations show that although higher levels of both attendance and interactivity behaviours are correlated with higher final grades, the correlation is stronger for the attendance behaviours than the interactivity behaviours. However, in the statistical models, which look at all five behaviours simultaneously, only attendance behaviours are correlated with final grades; the interactivity behaviours are not (RQ2).

Adding gender (RQ3) reveals otherwise hidden differences about the relationships between the five behaviours and final grades. First, despite the fact that females were more active than males and had higher grades overall, the course behaviours - represented by the latent factor engagement - have a considerably stronger correlation with males' final grades than with females' final grades. Second, although higher levels of attendance behaviours were associated with higher final grades for both genders, higher levels of interactivity behaviours were associated with high final grades for males but not for females.

The results partially confirm the constructivist belief that student-student interactivity contributes to learning outcomes, since when we move from bivariate correlations to statistical models, the relationship does not seem to hold for females. This is a puzzling finding. Why are the interactivity behaviours less important for females than males when females are so much more active? It seems possible that females approach their online courses differently from males (Yukselturk \& Bulut, 2009). For example, it may be that females in online learning situations have a more social orientation (Johnson, 2011; Arbaugh, 2000), or that females more than males focus on building relationships in such sites of interactivity as discussion forums (Rovai, 2001). In other words, females' diligence in reading and posting may not translate into higher grades. To find out if this is the case, we need qualitative analyses of both viewing and posting behaviours in order to see if males and females are indeed behaving differently. But we also need to note that it may be that there may be variables that we did not have access to, such as academic history, attitudes toward school, or internal locus of control in online courses (Lowes \& Lin, 2015), that would better explain all these behaviours.

In terms of the approach to the analysis, the literature cited in Section 2 has in every case assumed a simple one-layer relationship between each researcher's chosen learning behaviours and course performance. Structural equation modelling (SEM) allows additional layers (Gerow et al., 2010). This makes SEM a useful addition to the analysis of complicated relationships (Bollen \& Long, 1993; Kline, 2011) because it makes it possible to move beyond identifying the importance of individual behaviours toward further exploring the multifaceted complexities of online learning. 
There are a number of limitations to our use of this LMS data set. First, although LMS behaviours can provide insights into what is happening inside courses, they are a digital trail that provides at best a partial view. In addition, LMS output can differ from LMS to LMS, depending on the access architecture (Campbell \& Oblinger, 2007; Richards, 2011). We purposefully used LMS data easily available from most learning management systems and conducted relatively easy to replicate analyses. Other LMS output and other types of statistical analysis might provide additional (or different) insights. For example, we did not have any data on the number or timeliness of assignments submitted, which might have strengthened the attendance data since completing assignments strongly suggests course engagement. In addition, we did not have data from other types of student-student interaction, either inside the LMS (i.e., group work) or outside via Skype or in wikis or offline in study groups. Second, and equally important, we need to recognize that each behaviour variable may not represent the same behaviour for everyone. Attendance behaviours such as time in the system do not necessarily equate with time on task while there: some students may work offline and use their online time efficiently while others may login but not work steadily once there (Kovanović et al., 2015).

The next step in our research is to determine if these findings apply to the students in the next cohort. But in addition to replication, we need research on other age groups and populations, as well as qualitative analyses, in order to confirm (or not) the differences between attendance and interactivity behaviours, to determine in what circumstances gender plays a role, and in general to expand our understanding of how online behaviours are related to course outcomes.

\section{ACKNOWLEDGMENTS}

We would like to thank Pamoja Education for providing the data that made this analysis possible and for its support of the effort to make sense of it, and the Journal of Learning Analytics reviewers for their very helpful comments and suggestions.

\section{REFERENCES}

Anderson, T. (2003). Getting the mix right again: An updated and theoretical rationale for interaction. The International Review of Research in Open and Distributed Learning, 4(2). Retrieved from http://www.irrodl.org/index.php/irrodl/article/view/149/230

Arbaugh, J. B. (2000). An exploratory study of the effects of gender on student learning and class participation in an Internet-based MBA course. Management Learning, 31(4), 503-519. http://dx.doi.org/ 10.1177/1350507600314006

Bernard, R. M., Abrami, P. C., Borokhovski, E., Wade, C. A., Tamim, R. M., Surkes, M. A., \& Bethel, E. C. (2009.) A meta-analysis of three types of interaction treatments in distance education. Review of Educational Research, 79(3), 1243-1289. http://dx.doi.org/10.3102/0034654309333844

Bollen, K. A., \& Long, J. S. (Eds.). (1993). Testing structural equation models. Newbury Park, CA: SAGE Publications. 
(2015). Exploring the link between online behaviours and course performance in asynchronous online high school courses. Journal of Learning Analytics, 2(2), 169-194. http://dx.doi.org/10.18608/jla.2015.22.13

Campbell, J., \& Oblinger, D. (2007). Academic analytics. Washington, DC: Educause. Retrieved from https://net.educause.edu/ir/library/pdf/PUB6101.pdf

Chapman, E. (2003). Alternative approaches to assessing student engagement rates. Practical Assessment, Research \& Evaluation, 8(13). Retrieved from http://PAREonline.net/getvn.asp?v $=8 \& n=13$

Cho, M. H., \& Kim, B. J. (2013). Students' self-regulation for interaction with others in online learning environments. The Internet and Higher Education, 17, 69-75. http://dx.doi.org/10.1016/j.iheduc.2012.11.001

Davies, J., \& Graff, M. (2005). Performance in e-learning: Online participation and student grades. British Journal of Educational Technology, 35(4), 657-663. http://dx.doi.org/ 10.1111/j.14678535.2005.00542.x

Dawson, S., McWilliam, E., \& Tan, J. (2008). Teaching smarter: How mining ICT data can inform and improve learning and teaching practice. Hello! Where are you in the landscape of educational technology? Proceedings ASCILITE Melbourne 2008 (pp. 221-230). Retrieved from http://www.ascilite.org/conferences/melbourne08/procs/dawson.pdf

Gerow, J. E., Grover, V., Roberts, N., \& Thatcher, J. B. (2010). The diffusion of second generation statistical techniques in information systems research from 1990-2008. Journal of Information Technology and Application, 11(4), 5-28. Retrieved from http://works.bepress.com/jason_thatcher/25

Hung, J-L., \& Zhang, K. (2008). Revealing online learning behaviors and activity patterns and making predictions with data mining techniques in online teaching. MERLOT Journal of Online Learning and Teaching, 4(4), 426-437. Retrieved from http://jolt.merlot.org/vol4no4/hung_1208.pdf

Hung, J., Hsu, Y., \& Rice, K. (2012). Integrating data mining in program evaluation of K-12 online education. Educational Technology \& Society, 15(3), 27-41.

iNACOL (International Association for K-12 Online Learning). (2013). Fast facts about online learning. Vienna, VA: International Association for Online Learning. Retrieved from http://www.inacol.org/resource/fast-facts-about-online-learning/

iNACOL (International Association for K-12 Online Learning). (2011). Quality standards for online courses. Vienna, VA: International Association for Online Learning. Retrieved from http://www.inacol.org/resource/inacol-national-standards-for-quality-online-courses-v2/

International Baccalaureate. (2013). What Is an IB Education? Cardiff, Wales: International Baccalaureate Organization. Retrieved from http://www.ibo.org/globalassets/publications/what-is-an-ib-education-en.pdf

Johnson, R. D. (2011). Gender differences in e-learning: Communication, social presence, and learning outcomes. Journal of Organization and End User Computing, 23(1), 79-94. http://dx.doi.org/10.4018/joeuc.2011010105

Jonassen, D. H. (1999). Designing constructivist learning environments. In C. M. Reigeluth (Ed.), Instructional-design theories and models: A new paradigm of instructional theory (Vol. II, pp. 215-39). Mahwah, NJ: Lawrence Erlbaum Associates. 
(2015). Exploring the link between online behaviours and course performance in asynchronous online high school courses. Journal of Learning Analytics, 2(2), 169-194. http://dx.doi.org/10.18608/jla.2015.22.13

Kline, R. B. (2011). Principles and practice of structural equation modeling ( ${ }^{\text {rd }}$ ed.). New York: Gilford Press.

Kovanović, V., Gaŝević, D., Dawson, S., Joksimović, S., Baker, R., \& Hatala, M. (2015). Penetrating the black box of time-on-task estimation. Proceedings of the 5th International Conference on Learning Analytics and Knowledge (LAK '15), 184-193. http://dx.doi.org/10.1145/2723576.2723623

Leech, N. L., Barrett, K. C., \& Morgan, G. A. (2011). SPSS for intermediate statistics: Use and interpretation ( $4^{\text {th }}$ ed.). New York: Taylor \& Francis.

Liu, F., \& Cavanaugh, C. (2011a). High enrollment course success factors in virtual school: Factors influencing student academic achievement. International Journal on E-Learning, 10(4), 393-418.

Liu, F., \& Cavanaugh, C. (2011b). Success in online high school Biology: Factors influencing student academic performance. Quarterly Review of Distance Education, 12(1), 37-54.

Liu, F., \& Cavanaugh, C. (2012). Factors influencing student academic performance in online high school Algebra. Open Learning: The Journal of Open, Distance and e-Learning, 27(2), 149-167.

Lowes, S. (2014). A brief look at the methodologies used in researching online teaching and learning. In R. E. Ferdig \& K. Kennedy (Eds.), Handbook of research on K-12 online and blended learning (pp. 83-104). Pittsburgh, PA: ETC Press.

Lowes, S., \& Lin, P. (2015). Learning to learn online: Using locus of control to help students become successful online learners. Journal of Online Learning Research, 1(1), 17-48.

Macfadyen, L. P., \& Dawson, S. (2010). Mining LMS data to develop an "early warning system" for educators: A proof of concept. Computers \& Education, 54(2), 588-599. http://dx.doi.org/10.1016/j.compedu.2009.09.008

McSporran, M., \& Young, S. (2001). Does gender matter in online learning? Research in Learning Technology, 9(2), 3-15.

Muthén, L. \& Muthén, B. (2013). Statistical software [Computer software and manual]. Los Angeles, CA: Muthén \& Muthén.

Moore, M. (1989). Three types of interaction. American Journal of Distance Education, 3(2), 1-6. http://dx.doi.org/ 10.1080/08923648909526659

Morris, L. V., Finnegan, C., \& Wu, S-S. (2005). Tracking student behavior, persistence, and achievement in online courses. Internet and Higher Education, 8, 221-231.

NCES (National Center for Educational Statistics). (2005). Distance education courses for public elementary and secondary school students: 2002-2003. Washington, DC: NCES.

NCES (National Center for Educational Statistics). (2011). Distance education courses for public elementary and secondary school students: 2009-2010. Washington, DC: NCES.

Ramos, C., \& Yudko, E. (2008). "Hits" (not "Discussion Posts") predict student success in online courses: A double cross-validation study. Computers \& Education, 50(4), 1174-1182. http://dx.doi.org/10.1016/j.compedu.2006.11.003

Richards, G. (2011). Measuring engagement: Learning analytics in online learning. Paper presented at Electronic Kazan 2011, 19 April 2011, Kazan, Russian Federation. Retrieved from 
(2015). Exploring the link between online behaviours and course performance in asynchronous online high school courses. Journal of Learning Analytics, 2(2), 169-194. http://dx.doi.org/10.18608/jla.2015.22.13

https://www.academia.edu/779650/Measuring_Engagement_Learning_Analytics_in_Online_Le arning

Rovai, A. P. (2001). Building classroom community at a distance: A case study. Educational Technology Research and Development, 49(4), 33-48. http://dx.doi.org/10.1007/BF02504946

Ryabov, I. (2012). The effect of time online on grades in online sociology courses. MERLOT Journal of Online Learning and Teaching, 8(1), 13-23. Retrieved from http://jolt.merlot.org/vol8no1/ryabov_0312.htm

Southern Regional Education Board. (2006). Standards for quality online courses. Atlanta, GA: SREB.

Voyer, D., \& Voyer, S. D. (2014). Gender differences in scholastic achievement: A meta-analysis. Psychological Bulletin, 140(4), 1174-1204. http://psycnet.apa.org/doi/10.1037/a0036620

Wang, A. Y., \& Newlin, M. H. (2000). Characteristics of students who enroll and succeed in psychology web-based classes. Journal of Educational Psychology, 92(1), 137-143.

Watson, J., Pape, L., Murin, A., Gemin, B., \& Vashaw, L. (2014). Keeping pace with K-12 digital learning. Durango, CO: Evergreen Educational Group.

Wei, H.-C., Peng, C., \& Chou, C. (2015). Can more interactivity improve learning achievement in an online course? Effects of college students' perception and actual use of a course-management system on their learning achievement. Computers \& Education, 83, 10-21. http://dx.doi.org/10.1016/j.compedu.2014.12.013

Yukselturk, E., \& Bulut, S. (2009). Gender differences in self-regulated online learning environments. Educational Technology \& Society, 12(3), 12-22. 


\section{APPENDIX}

When we compare CFA Model 1 (without gender) to CFA Model 2 (gender considered), the smaller AIC/BIC information criteria suggest that the model that considers gender fits the data better. (For CFA Model 2, the Chi-square contribution was 9.610 for males and 12.306 for females.) Note that although CFA Model 1a (for females only) and CFA Model 1b (for males only) fit the data well, they are only for reference because breaking the students into two groups would introduce Type 1 error.

Table 1. Model fit indices (CFA Models 1-4).

\begin{tabular}{lccccccccc}
\hline Model & AIC & BIC & $\boldsymbol{X}^{2}$ & $\boldsymbol{d} \boldsymbol{f}$ & Sig. of $\boldsymbol{X}^{2}$ & RMSEA (90\% CI) & CFI & TLI & SRMR \\
\hline CFA Model 1 & 7583.644 & 7665.278 & 4.006 & 2 & .135 & $.038(.000-.093)$ & .999 & .995 & .006 \\
CFA Model 1a & 4293.416 & 4364.528 & 2.881 & 2 & .237 & $.034(.000-.113)$ & .999 & .996 & .007 \\
CFA Model 1b & 3210.583 & 3277.549 & 2.130 & 2 & .345 & $.015(.000-.115)$ & 1.000 & .999 & .006 \\
CFA Model 2 & 7504.904 & 7631.891 & 21.196 & 12 & .039 & $.049(.011-.081)$ & .995 & .992 & .028 \\
\hline
\end{tabular}

When we compare SEM Model 1 to SEM Model 2, the model fit indices suggest that the model considering gender provide a better fit. (For SEM Model 2, the Chi-square contribution was 16.260 for males and 13.025 for females.)

Table 2. Model fit indices (SEM Models 1 and 2).

\begin{tabular}{lccccccc}
\hline Model & $\boldsymbol{X}^{2}$ & $\boldsymbol{d f}$ & Sig. of $\boldsymbol{X}^{2}$ & RMSEA (90\% Cl) & CFI & TLI & SRMR \\
\hline SEM Model 1 (no gender) & 13.690 & 6 & .033 & $.040(.011-.069)$ & .995 & .988 & .339 \\
SEM Model 2 (with gender) & 29.285 & 20 & .082 & $.034(.000-.059)$ & .994 & .990 & .641 \\
\hline
\end{tabular}

When we compare SEM Model 3 to SEM Model 4, the model fit indices suggest that the model considering gender provide a better fit. (For SEM Model 4, the Chi-square contribution was 11.460 for males and 12.233 for females.)

Table 3. Model fit indices (SEM Models 3 and 4).

\begin{tabular}{lccccccc}
\hline Model & $\boldsymbol{X}^{2}$ & $\boldsymbol{d f}$ & Sig. of $\boldsymbol{X}^{2}$ & RMSEA (90\% CI) & CFI & TLI & SRMR \\
\hline SEM Model 3 (no gender) & 17.845 & 5 & .003 & $.057(.030-.086)$ & .992 & .975 & .335 \\
SEM Model 4 (with gender) & 23.694 & 16 & .096 & $.035(.000-.062)$ & .995 & .990 & .492 \\
\hline
\end{tabular}

Below are the model fit indices (Table 4), as well as the conceptual model and parameter estimates (Figure 1), for the alternative model:

Table 4. Model fit indices (SEM alternative model).

\begin{tabular}{lccccccc}
\hline Model & $\boldsymbol{X}^{2}$ & $\boldsymbol{d f}$ & Sig. of $\boldsymbol{X}^{2}$ & RMSEA (90\% CI) & CFI & TLI & SRMR \\
\hline Gender as factor & 17.710 & 10 & .060 & $031(.000-.054)$ & .995 & .990 & .414 \\
\hline
\end{tabular}


(2015). Exploring the link between online behaviours and course performance in asynchronous online high school courses. Journal of Learning Analytics, 2(2), 169-194. http://dx.doi.org/10.18608/jla.2015.22.13

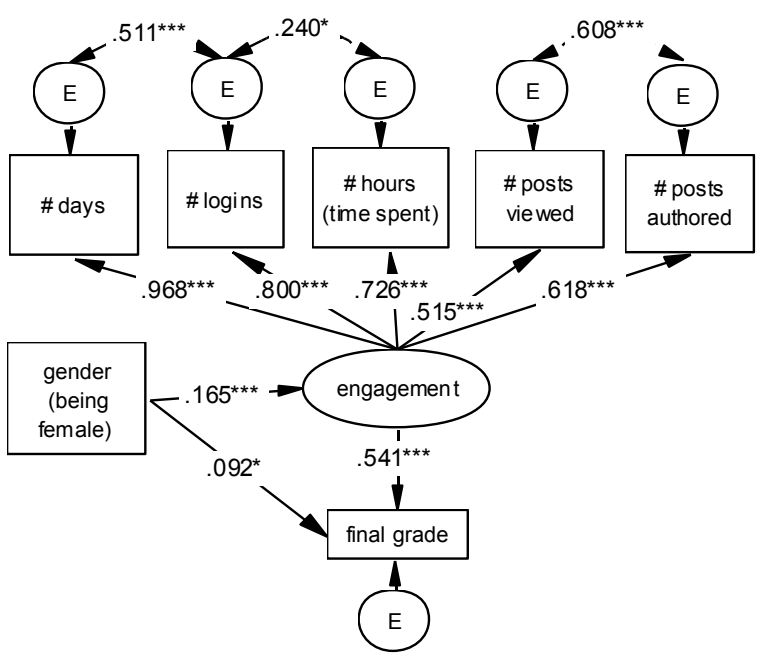

Figure 1. Standardized parameter estimates for the alterative model (gender difference). 